\title{
Uma perspectiva nietzschiana sobre liberdade e necessidade*
}

\author{
Miguel Angel de Barrenechea**
}

Resumo: Abordamos a interpretação nietzschiana sobre "liberdade" e "necessidade" e como o filósofo contesta noções da tradição, vinculadas a essa problemática: "causa e efeito", "sujeito", "vontade", etc. Ele assinala como esses conceitos seriam construtos antropomórficos que não conseguem desvendar as ações geridas apenas pela dinâmica da vontade de potência. Mostramos que Nietzsche, mesmo com sua crítica aos conceitos da tradição, continua empregando noções como "fatalidade", "necessidade", que parecem reeditar uma conceituação antropomórfica. Indicamos como ele ultrapassa objeções passíveis de serem feitas a um pensamento oscilante, que parece negar e afirmar a liberdade. Concordamos com intérpretes que destacam como seu estilo suscita deliberadamente paradoxos e aporias, já que seu objetivo, antes que estabelecer uma doutrina ou

* Este artigo apresenta algumas reflexões vinculadas à pesquisa: "Grande política: Nietzsche e o diálogo filosófico contemporâneo". Nele, retomamos questões articuladas com o problema da causalidade, da necessidade e da liberdade; questões que abordamos, há algum tempo, no livro Nietzsche e a liberdade (BARRENECHEA, 2008). Destacamos, também, que o diálogo no II Colóquio Nietzsche, organizado pelo Grupo de Estudos Nietzsche (GENi) - UECE, em Fortaleza-CE, em dezembro de 2019, foi relevante para reformular diversas ideias sobre o tema principal deste trabalho. Destacamos o fecundo diálogo que se seguiu a cada uma das palestras, como a de Matteoli, "O que há de verdade na ciência e como ela é possível em meio ao erro?", que gerou uma valiosa troca, particularmente em torno das noções de causalidade, necessidade e liberdade em Nietzsche, e também as ponderações de Pimenta e Lopes, que contribuíram com o amadurecimento das teses deste artigo

** Professor Titular da Faculdade de Filosofia da Unirio, Brasil. Correio Eletrônico: miguelangelbf12001@yahoo.com.br ORCID: https://orcid.org/0000-0001-8172-5027 
Uma perspectiva nietzschiana sobre liberdade e necessidade

uma teoria consolidada, visa instigar novas reflexões e experiências de pensamento sobre $\mathrm{o}$ agir do homem.

Palavras-chave: perspectivas, liberdade-necessidade, causalidade, sujeito, vontade.

\section{Introdução}

Pensando na minha genealogia filosófica, sinto-me relacionado (...) com o movimento mecanicista (redução de todas as questões morais e estéticas a outras fisiológicas, de todas as questões fisiológicas a outras químicas, de todas as questões químicas a outras mecânicas), mas com a diferença de que não creio na "matéria" (...). (Nachlass/FP, verão-outono de 1884, 26 [432], KSA, KSA 11.266).

A proposta deste artigo é refletir sobre a articulação entre as noções de necessidade e liberdade no pensamento de Nietzsche ${ }^{1}$. Esses termos aparecem vinculados na filosofia do pensador alemão, e permitem refletir sobre as ações do homem a partir de uma ótica singular ${ }^{2}$. Essa ótica articula-se com o conceito de vontade de potência, central na teoria nietzschiana ${ }^{3}$. Nessa perspectiva não é

1 Consideramos as definições, apresentadas em Dicionário de Filosofia, organizado pelo GEN, sob a coordenação de Scarlett Marton (2016), uma importante contribuição para uma introdução à elucidação de conceitos nucleares de Nietzsche. Neste artigo, levamos em conta, principalmente, as noções de: "causalidade" (Kausalität, Ursächlichkeit) e "livre arbítrio" (freier Wille, Freiheit des Willens, Willensfreiheit), claramente apresentadas por André Itaparica (p. 137-139, 288-290); além de "necessidade" (Notwendigkeit), adequadamente esclarecida por Eduardo Nasser (p. 324-326).

2 Em Nietzsche e a liberdade (Barrenechea, 2008), sustentamos que o autor alemão tenta ultrapassar a aporia que existiria na afirmação da liberdade articulada com a necessidade: “(...) a liberdade (...) consiste na aceitação da necessidade, na adesão às forças terrestres. (...) Há uma articulação essencial entre a liberdade, entendida como afeição incondicional à fatalidade, ao processo de criação artística.” (p. 11). Retomamos agora as relações entre necessidade e liberdade sob outros vieses. Destacamos a importância de rediscutir essa questão pela complexidade da interpretação de Nietzsche sobre o tema, que na ótica de diversos intérpretes, como Dias, leva a labirintos conceituais, até mesmo a forjar "mitologias": "Para Nietzsche, a crença no livre-arbítrio repousa em falsas interpretações - é da ordem da mitologia.” (Dias, 2011, p. 114).

3 Optamos por definir Macht como potência, divergindo da opção de intérpretes que a traduzem como poder, lembrando que pela grande diversidade semântica do termo Macth, em português,

Cad. Nietzsche, Guarulhos/Porto Seguro, v.41, n.3, setembro-dezembro $2020 \mid 101$ 
possível separar homem e mundo: "já rimos, ao ver 'homem e mundo', colocados um ao lado do outro, separados tão só pela sublime presunção da palavrinha 'e'." (FW/GC, 346, KSA 3.579). Homem e mundo formam parte do mesmo processo do desenrolar da vontade de potência ${ }^{4}$. Desse modo, não é possível afirmar a existência de dois âmbitos cindidos: de um lado um mundo que estaria regido por uma ordem causal, com leis rígidas e imutáveis, que determinariam um reino da necessidade e, de forma totalmente diversa, haveria um ser que foge a toda determinação, o homem, que possuiria uma vontade autônoma, livre de toda constrição das forças naturais $^{5}$. Nietzsche frisa, desde o início de sua obra, que o homem é essencialmente natureza e, como parte dela, partilha suas características de regularidade, irregularidade, ordem ou desordem. Se há

pode ser entendido tanto como potência quanto poder. Justificamos a nossa escolha, de forma mais detalhada, nos nossos livros Nietzsche e a liberdade (Barrenechea, 2008, p. 17) e Nietzsche e o corpo (Barrenechea, 2017, p. 59), afirmando: “(...) optei por traduzir Macht por potência que, em português, tem um sentido mais abrangente (há potência no homem, nos animais e até no âmbito inorgânico), já que a noção de poder alude mais especificamente à esfera humana: poder militar, econômico e outros." Relembramos uma das mais claras caracterizações da vontade de potência: "Esse mundo é vontade de potência - e nada além disso! E vós próprios sois essa vontade de potência - e nada além disso!" (Nachlass/FP, junho-julho de 1885, 38 [12], KSA11.610). O conceito de vontade de potência será crucial para a questão da liberdade; para nós, não é uma entidade metafísica que subjaz às forças, mas “o próprio processo de efetivação das forças, não algo exterior a elas. (...) o próprio jogo, a própria dinâmica dessas interações, mas não um jogo que exista - precedente ou subjacente - fora dessas composições de forças, não é transcendente às forças." (Barrenechea, 2017, p. 80-81).

4 Stegmaier (2013, p. 44) encontra no conceito de Si mesmo (Selbst), quando Nietzsche alude ao corpo, a possibilidade de interpretar corpo e mundo como um circuito reciprocamente condicionado, diferente de um "eu" abstrato, isolado da exterioridade: "Nietzsche pensa o entrelaçamento e o caráter reciprocamente condicionado entre corpo e mundo no conceito de si mesmo. Si mesmo significa colocar-se-em-relação-de-si-para-si do corpo as condições de seu mundo: o si mesmo suprime em si a autorreferencialidade abstrata do eu."

5 Nasser (2016, p. 324-365) mostra que Nietzsche parece aproximar-se, no início de sua obra, a uma "espécie de determinismo", em que o homem estaria submetido à necessidade: "O amadurecimento dessa posição está diretamente relacionado ao desenvolvimento de uma violenta crítica à vontade livre"; contudo, vontade livre é uma "concepção simplificadora, sendo, assim, a crença de que os acontecimentos são movidos por motivos e por agentes responsáveis. Logo, tudo deve se dar por necessidade" (p. 325). Nasser afirmará posteriormente, que a noção de causalidade, base de todo determinismo, não passa de uma ficção: "o elo entre necessidade e causalidade é desfeito, devolve-se o acaso, ou a inocência dos acontecimentos” (p. 325). 
Uma perspectiva nietzschiana sobre liberdade e necessidade

causalidade, caos, acaso, determinação ou liberdade, acontecem tanto no mundo quanto no homem; pois o homem é parte do mundo, não é um ser excepcional, alheio às forças dessa dinâmica da natureza ${ }^{6}$. Em outro sentido, o pensador alemão contesta que exista uma identidade do homem, entendida como consciência, como a permanência de um eu ou um substrato subjetivo que constituiria a individualidade humana: "E o que dizer do Eu! Ele se tornou uma fábula, uma ficção, um jogo de palavras (...)." (GD/CI, Os quatro grandes erros, 3, KSA 6.91) ${ }^{7}$.

Como apontamos anteriormente, tanto o homem quanto a natureza são vontade de potência e "nada além disso". O conceito de vontade de potência permite interpretar todas as forças que perfilam tanto o homem quanto o mundo ${ }^{8}$. Mas, vale retomar uma importante e difícil questão: será possível penetrar, por intermédio dos conceitos da tradição filosófica, na dinâmica da vontade

6 Desde $O$ nascimento da tragédia, Nietzsche mostra que o homem está absolutamente inserido na Natureza, como uma das configurações do jogo de impulsos dionisíacos e apolíneos; isso fica claro no primeiro capítulo dessa obra, quando mostra como o homem está ligado à totalidade, no fenômeno do dionisíaco: "Sob a magia do dionisíaco torna a selar-se não apenas o laço de pessoa a pessoa, mas também a natureza alheada, inamistosa ou subjugada volta a celebrar a festa de reconciliação com seu filho perdido, o homem. Espontaneamente oferece a terra as suas dádivas e pacificamente se achegam as feras da montanha e do deserto." (GT/NT, 1, KSA 1.29). Destacamos o comentário sobre o conceito de Natureza (Natur), de Araldi, no Dicionário Nietzsche (GEN, 2016, p. 322-324). Lembremos que, nas etapas posteriores do pensamento de Nietzsche, já afastado das influências de Wagner e Schopenhauer, o filósofo alemão sempre destaca a total inserção do homem na natureza; como destaca Löwith (1985, p. 154-155): "O que importa aqui é que o homem seja recolocado na natureza, no conjunto das coisas (...)."

7 No nosso livro Nietzsche e a liberdade (Barrenechea, 2008), particularmente no capítulo II, (p. 47-79), abordamos a crítica nietzschiana a diversos conceitos que aludem, na tradição filosófica, a uma suposta consistência "interna" no homem, tais como "sujeito", "eu”, "consciência", entre outras.

8 Na compreensão da vontade de potência, concordamos com a leitura de alguns autores, como Muller-Lauter (1997, p. 74, 96), que define esse conceito como oposição e concerto de vontades: "A vontade de poder é a multiplicidade das forças em combate umas com as outras"; trata-se de um "jogo de oposição e concerto de muitas vontades de poder, de todo modo, organizadas em unidade"; também nos aproximamos da interpretação de Itaparica (2019, p. 134) que entende vontade de potência como algo não material, como a atividade da força: "Esta qualidade interna [a vontade de potência] não é nada mais que a própria atividade. Força e vontade de potência (...) só podem ser identificadas se compreendermos as forças como algo não material (...), cuja natureza consiste na própria atividade."

Cad. Nietzsche, Guarulhos/Porto Seguro, v.41, n.3, setembro-dezembro $2020 \mid 103$ 
de potência? Não estaremos tecendo apenas noções antropomórficas para tornar compreensível, inteligível, esse incessante jogo de forças, do fluxo permanente do devir? ${ }^{9}$ Nietzsche sustenta - em diálogo com as ciências da época ${ }^{10}$ - que tanto as perspectivas mecanicistas quanto as teleológicas são tentativas ficcionais de "ordenar", de "enquadrar" o fluxo do mundo em um marco conceitual. As denominadas relações causais e os supostos fins na natureza são criações humanas para tentar impor regularidade e ordem naquilo que é puro movimento e contínua instabilidade. Nesse sentido, a crítica da noção de causa efeito se apoia na perspectiva de que tudo é fluxo, desordem, $\operatorname{caos}^{11}$.

A noção de caos pode ser pensada como a dinâmica decorrente da permanente mobilidade da vontade de potência, que em cada encontro pontual de forças produz novas relações, novas con-

9 Nietzsche sustenta que qualquer tese, ou conceituação do mundo, é apenas um construto antropomórfico, produzido pelas necessidades vitais, de um animal inteligente. Ele desenvolve essa perspectiva no importante opúsculo de 1873, Verdade e mentira no sentido extra moral. 0 filósofo alemão sustentará, por outras vias argumentativas, após essa obra juvenil, a desconfiança em toda e qualquer conceituação, que pretenda corresponder à verdade de um mundo, em si mesmo, que supostamente estaria para além da nossa atividade interpretativa; em todo conceito apresentamos nossa interpretação, nossa visão sobre aquilo que denominamos "as coisas": "O surgimento das coisas é, de fato, obra de seres que representam, pensam, querem, inventam." (Nachlass/FP, Outono de 1885 - Outono de 1886, 2 [152], KSA 12.141).

10 Para esclarecer essa questão, destacamos o trabalho de Lemm (2009), quando aborda a animalidade em Nietzsche, assim como os livros de Stiegler (2001, 2005), que analisam os vínculos de Nietzsche com a biologia e com as ciências em geral da sua época; destacamos também a coletânea que organizamos Nietzsche e as ciências (Barrenechea, 2011), onde diversos artigos abordam o diálogo de Nietzsche com as ciências, que teve grande relevância na constituição de sua proposta filosófica. É importante indicarmos, entre esses artigos, "Filosofia e ciência: Nietzsche herdeiro do programa de Friedrich Albert Lange", de Rogério Lopes e "Da biologia à física: vontade de potência e eterno retorno do mesmo. Nietzsche e as ciências da natureza" de Scarlett Marton.

11 Nietzsche questiona e nega toda e qualquer efetividade à noção de causa e efeito; na qual acreditamos a partir da crença na nossa própria atividade subjetiva, na fé em que é a nossa "alma" é atuante, que produz "efeitos": "A crença na causalidade remete à crença de que sou eu que atua, à distinção da 'alma' e sua atividade. Trata-se, portanto, de uma superstição imemorial!" (Nachlass/FP, Outono de 1885-Primavera de 18861 [38], KSA 12.19). Encontramos em Crepúsculo dos ídolos, particularmente em "Os quatro grandes erros", uma crítica minuciosa e contundente à compreensão causal dos "eventos". Ele contesta conceitos como "vontade livre", "motivo da ação", "espírito", "sujeito", que seriam fábulas ou jogos de palavras. 
Uma perspectiva nietzschiana sobre liberdade e necessidade

figurações de poder; assim, no devir não encontramos regularidade, ordem nem causalidade. Porém, o homem pretende ordenar, "tornar regular" esse processo dinâmico, acreditando e afirmando a existência de entidades estáveis. Ele emprega conceitos que visam detectar "identidades", "permanências" no mar de forças da vontade de potência. Essas noções afirmam que os supostos "entes" do mundo estariam regidos por relações de causa-efeito, de leis, de processos constantes e previsíveis. Nietzsche questiona todo esse aparato conceitual; no devir não haveria nenhuma relação mecânica, nenhuma finalidade, nenhuma relação de causa-efeito, nenhuma entidade; todos esses construtos conceituais pretendem apontar a existência de "fins" e "causas"12; mas talvez, com nosso aparelho de noções, nada saibamos do devir das forças: "talvez não haja mais do que um único reino; talvez sejamos nós que as inventamos. As mãos de ferro da necessidade que agitam os dados do acaso seguem indefinidamente seu jogo." (M/A, 130, KSA 3.122). O jogo de forças é alheio a todas as tentativas de organizar e sistematizar um mundo em devir, um mundo não humano, que se apresenta caótico para nosso entendimento: “A condição geral do mundo é, por outro lado, por toda a eternidade o caos, não pela falta de necessidade, mas no sentido de uma falta de ordem, de estrutura, de forma, de beleza, de sabedoria e como quer que se chamem nossos antropomorfismos estéticos." (FW/GC, 109, KSA 3.468).

A partir dessa compreensão do devir, entendido como movi-

12 Nietzsche sustenta que a "regularidade", a "legalidade", não exprime qualquer ordem ou constância na natureza, apenas manifesta que, na nossa experiência, na nossa percepção temporal, percebemos estados que se sucedem e repetem e daí imaginamos a existência de leis, regras: "A "regularidade" da sucessão é apenas uma expressão figurativa, como se aqui se estivesse seguindo uma regra: não é um estado de fato. Da mesma forma a "legalidade". Buscamos uma fórmula para expressar um tipo de sucessão que se repete constantemente: (...) não descobrimos nenhuma lei, muito menos uma força que seria a causa destas sucessões repetidas. O fato de que alguma coisa aconteça sempre de tal forma (...) é aqui interpretado como se um ser, em obediência a uma lei ou a um legislador, sempre agiria de tal e tal maneira." (Nachlass/ FP, Outono de 1885 - Outono de 1886, 2 [142], KSA 12.137). Itaparica (2019, p. 81-82) esclarece que, a partir da percepção do tempo, e de nossa crença na substância, que supõe coisas que permanecem, após estados sucessivos, surgem as noções de coisa e causalidade. Contudo, “a relação causal não é uma 'explicação', e sim uma 'descrição' de estados sucessivos."

Cad. Nietzsche, Guarulhos/Porto Seguro, v.41, n.3, setembro-dezembro $2020 \mid 105$ 
mento permanente de forças, todo conceito que alude a entidades permanentes seria apenas uma ferramenta antropomórfica, carente de qualquer correspondência com esse movimento. Nietzsche questiona que exista algo assim como a "necessidade", entendida como a legalidade que regularia a ação de entidades, conhecidas como "coisas", "entes" ou "átomos", numa interação de supostas relações de causa-efeito ou ação e reação. O termo "necessidade" deve ser considerado um instrumental antropomórfico que nos leva a acreditar que há um mundo ordenado, previsível. O homem não seria livre nem determinado, essas noções decorrem exclusivamente de interpretações que servem apenas para melhor nos orientar no mundo.

\section{Em que sentido poderia ainda empregar-se o conceito de ${ }^{6}$ liberdade"?}

É importante, na sequência, a partir das teses levantadas acima, refletir sobre a situação do homem para indagar se ele teria (ou não) a capacidade de agir, de produzir atos. Seria possível afirmar em algum sentido - após apontar o antropomorfismo dessas noções - que o homem é livre ou determinado? O filósofo alemão questiona todos os termos que aludem a uma suposta capacidade do homem para agir de forma autônoma. Não haveria um sujeito, um eu, uma consciência ou uma vontade, "responsável" pelas ações do ser humano. Para continuar na elucidação da questão da liberdade, parece importante retomarmos a questão do significado da noção de vontade livre; então indagamos, mesmo com as ressalvas colocadas anteriormente: ainda teria sentido afirmar que o ser humano poderia agir conforme suas próprias decisões? Na resposta da tradição filosófica idealista, a vontade seria causa de si, agiria de forma independente no mundo, operaria de uma forma "mágica", alheia a qualquer determinação ou imposição das forças ${ }^{13}$. Susten-

13 Kant é um exemplo paradigmático de um pensador idealista que está ciente das dificul- 
Uma perspectiva nietzschiana sobre liberdade e necessidade

tar a existência de uma vontade autônoma traz novamente à tona a noção de causa e efeito. Nesse sentido, a vontade seria capaz de produzir efeitos, sem estar condicionada por nenhuma causa antecedente. Como já foi dito, na ótica nietzschiana, não haveria causas nem efeitos, apenas forças interagindo. Então, a vontade humana seria outra ficção, que nos faz acreditar que somos protagonistas ou causa de ações: “O 'mundo interno' está cheio de ilusões e fogos fátuos: a vontade é um deles. A vontade não movimenta nada, e, por conseguinte, também no esclarece nada." (GD/CI, "Os quatro grandes erros", 3, KSA 6.91). Em outras palavras, Nietzsche questiona a noção de liberdade, entendida como a capacidade operativa da vontade humana, assim como contesta as noções de determinismo ou necessidade, por serem construtos antropomórficos baseados ainda em supostas relações causais: "No 'em si’ não há nenhum vestígio de 'nexo causal', de 'necessidade', de 'determinismo psicológico', o ‘efeito' não é consequência de nenhuma 'causa', nenhuma 'lei' impera ali." (JGB/BM, 21, KSA 5.35).

Observamos que a "determinação" da vida humana é contestada, mas, por outra parte, em outros textos nietzschianos parece afirmada. No parágrafo acima, de Além de bem e mal, vimos que são criticadas as noções de causalidade, lei, necessidade, determinismo psicológico, etc. Contudo, encontramos numerosas passagens nas quais o filósofo alemão torna a empregar esses termos. Nestas, ele considera o homem como resultado, como produto de relações causais, de pressões químicas ou físicas, de tal forma que todos os atos do homem seriam "efeitos" de forças inorgânicas: "O inorgânico nos condiciona totalmente: a água, o ar, o solo, a confi-

dades de sustentar a ação de uma "causa livre", de uma vontade autônoma, em um mundo fenomênico regido por "leis naturais". Dai que na Crítica da razão pura (1979), na 3" Antinomia da Razão Pura, mostre a situação aporética para o pensamento teórico de afirmar que o homem seria agente, ou causa, em um mundo fenomênico regido por causas naturais, já que sempre estaria predeterminado por fatos antecedentes (Kant, 1979, p. 156-162). Sua saída seria considerar, pelo viés da razão prática, como afirma na Crítica da razão prática (1997), o ser humano livre, no plano numenal para além do mundo fenomênico: "a razão prática, por si mesma, e sem se ter associado com a [razão] especulativa, confere realidade a um objeto suprassensível da categoria da causalidade, a saber, à liberdade (...).” (Kant, 1997, p. 14).

Cad. Nietzsche, Guarulhos/Porto Seguro, v.41, n.3, setembro-dezembro 2020|107 
guração do terreno, a eletricidade etc. Somos plantas sujeitas a tais condições." (Nachlass/FP, Primavera-Outono 1881, 11[210], KSA 11.525). Em outro fragmento póstumo, as ações humanas são consideradas oriundas de fatores inorgânicos, até se sustentaria que todas as nossas vicissitudes vitais - incluindo o pensamento - dependeriam da quantidade de sal que haveria no organismo:

Proclamamos enfaticamente a nossa dessemelhança e superioridade a respeito do morto, do inorgânico, quando somos num setenta e cinco por cento uma coluna de água e contemos sais inorgânicos que talvez nos influenciem em maior medida que toda a sociedade vivente. (FP, Primavera-Outono de 1881, 11[207], KSA 11.524).

Além do propósito evidentemente irônico e cínico contido nessas afirmações - um dos principais objetivos é escarnecer de toda uma tradição metafísica e teológica que idealizou a condição do homem ${ }^{14}$-, devemos destacar que a tese da dependência dos processos psíquicos e orgânicos de atividades inorgânicas aparece com frequência em diversos fragmentos póstumos. Poderíamos entender essa ênfase na valorização do inorgânico na vida humana, ainda como uma aproximação de uma interpretação causal e determinista do homem? Os textos aludidos parecem indicar essa direção interpretativa.

Segundo a análise que realizamos até agora, a concepção da liberdade - entendida em termos de uma tradição que considera livre um sujeito autônomo, com uma vontade independente - não teria lugar na concepção do filósofo alemão. Se Nietzsche alude à liberdade, somente poderíamos pensá-la numa acepção totalmente

14 Fink (1983) destaca que Nietzsche combate todas as falácias idealistas que o homem construiu sobre si mesmo; ele ataca com extrema virulência, com profundo cinismo, toda idealização da "natureza humana"; o homem é animal entre animais, determinado exclusivamente pelos seus condicionamentos biológicos: "O cinismo de Nietzsche tem qualquer coisa de traição, pois não se trata de um zoólogo ingênuo que situa o homem no reino animal. (...) Com uma alegria diabólica empreende o combate contra todas as falácias idealistas que o homem constrói de si mesmo.” (p. 170). Blondel (1985, p. 308), por sua vez, frisa que o filósofo alemão seria muito mais do que um médico (medizynisch) da civilização, mas um cínico (zynisch) "quando fala da causa fisiológica do ideal". 
peculiar, sui generis. O homem não teria essa capacidade de atuar de forma autônoma, isolado do jogo contínuo das forças da vontade de potência. Ao rejeitarmos noções da tradição idealista, como "sujeito", "vontade", "consciência" e outras relativas a uma suposta identidade no homem, podemos ainda indagar: Nietzsche afirmaria a liberdade de quê ou de quem? Ao falarmos dos atos humanos, negamos qualquer substancialidade "interna" passível de produzir atos, e ao admitirmos a ação da vontade de potência em tudo o que existe, então procederia perguntar: seriam livres as forças? Lembremos que todo encontro de forças é gerido apenas pelo acaso, por uma imprevisível e sempre cambiante composição dinâmica que não poderia, de forma alguma, ser considerada como livre ou autônoma. Liberdade, no jogo espontâneo de cada composição de forças, poderia ser entendida apenas como o triunfo pontual, momentâneo, de um grupo de forças; seria como vencer uma disputa, nunca poderia ser entendido como uma escolha, uma decisão. Então, liberdade poderia adquirir outro significado: seria a imprevisão ou incerteza do resultado de uma luta?

Todavia, ainda seria factível continuar indagando: a força ou o grupo de forças vencedoras, em cada instante pontual, poderiam ser considerados "livres", ao imporem seu interesse, sua vontade específica? Toda força vencedora - ou, ainda, a vencida - responde apenas à dinâmica da vontade de potência. Nessa linha de pensamento, poderíamos, ainda, predicar "liberdade" da vontade de potência? Não obstante, vontade de potência não é um agente, não é um ente, carece de "intenções", ou mesmo de um "desejo" de vitória. A sua dinâmica decorre do processo de intensificação de forças - de aumento e diminuição destas - sem nenhuma finalidade pré-estabelecida, sem nenhuma ordem, regularidade ou legalidade, sua dinâmica segue exclusivamente o jogo do acaso.

Por esse motivo, atribuir "liberdade" à vontade de potência consiste em outro antropomorfismo questionável, parece outra tentativa de humanizar o devir, que, conforme seu permanente di- 
namismo, seria refratário a toda conceituação, através de termos oriundos da tradição metafísica. Em síntese, após as ponderações anteriores, é plausível levantar, ainda, diversas questões em torno da concepção nietzschiana de liberdade. Às vezes, essa liberdade, conforme entendida pela tradição idealista, é contestada de forma categórica, contudo, em outros momentos, a liberdade parece reaparecer no discurso nietzschiano, mesmo se acreditarmos que poderia ser atribuída à vontade de potência.

\section{Sobre a criação}

O problema da liberdade no pensamento de Nietzsche pode ser enfocado a partir de outros vieses para tentar equacionarmos algumas ambiguidades que parecem surgir nos seus textos. Para avançarmos nesse problema, vale ressaltar como a questão da avaliação, da criação de valores, se vincula à reflexão sobre o "livre arbítrio". O tema axiológico é central no pensamento de Nietzsche: a avaliação e a criação de novos parâmetros é um assunto relevante, desde o início da obra do filósofo do Zaratustra ${ }^{15}$. A criação de valores pode vincular-se ao problema da liberdade? Se há criação de valores, haveria, então, um agente produtor destes? Nesse ponto, é possível retomarmos questionamentos vinculados ao problema da liberdade e da necessidade. Tentaremos ver como Nietzsche se posiciona perante a problemática axiológica, e em que medida essa questão se vincula à capacidade humana de agir (ou não) de forma autônoma.

$\mathrm{O}$ que fica fora de qualquer contestação, nessa complexa problemática, é a afirmação de que avaliar é um processo permanente. Tudo aquilo que considerarmos como "real", que julgamos ou avaliamos é resultado de uma apreciação, de uma interpretação humana. E toda interpretação decorre de afetos, de um grupo de forças que impõem sua própria avaliação. Cada momento vital estabelece

15 Neste ponto é importante aludir à tese de Fink (1983, p. 15), quando destaca que, para Nietzsche, a questão axiológica "recobre" o problema ontológico: "ele não põe a questão do ser (...) o problema do ser é recoberto pelo problema do valor." 
uma perspectiva, uma nova apreciação do devir. Ora, se há avaliação, criação de valores, geração de novas perspectivas, é possível indagar: quem avalia? Quem interpreta? Não é um sujeito, uma vontade autônoma, não é um indivíduo interpretante. Cada avaliação é resultado de uma modalidade da vontade de potência, de forças e afetos triunfantes: "Não corresponde perguntar: 'quem interpreta', ao contrário, mas que a interpretação em si mesma, sendo uma modalidade da vontade de potência', está em existência (mas não como 'ser', senão como processus, como devir) sob a forma de afeto." (Nachlass/ FP, Outono 1885-Outono 1886, 2 [151], KSA 12.140).

A avaliação é resultado da vontade de potência. Esta tese aparece formulada repetidas vezes, e de forma categórica, nos textos de Nietzsche. O homem é "criador" de valores, não por ser autônomo ou espontâneo nesse processo, mas por responder e "acatar" afetos. Criar ou avaliar é "escutar" uma determinada configuração de forças, uma determinada flutuação da vontade de potência. O artista, por exemplo, não é fazedor ou criador ex nihilo, caso entendermos fazer ou criar como agir sem compulsão, sem antecedentes. Esse criador plasma e configura (em uma poesia, pintura, dança, etc.) a tendência de um afeto ou grupo de afetos dominantes; em outras palavras, ele "obedece" a vontade de potência. Mas haveria alternativa? Poderia o artista agir de outro modo, não avaliar da forma em que mensura cada momento vital; poderia realizar "escolhas", independentemente da dinâmica da vontade de potência? Não, isso implicaria a aceitação do agir de um agente individual, causa de si, que operaria para além do jogo das forças, para além de todo movimento da vontade de potência. Esse tipo de autonomia ou independência no agir é contestado por Nietzsche.

Então, reformulamos a questão: em que sentido é possível entendermos a criação? Quem cria quando afirmamos que o homem cria? $\mathrm{Na}$ perspectiva nietzschiana, fica claro que a criação adquire um novo sentido, o homem criador é entendido como um médium, um instrumento do jogo de forças: "Ao falar de valores, é 
a vida mesma que nos força a estabelecer valores, ela mesma valora através de nós ao estabelecermos valores." (GD/CI, "A moral como contra natureza", 5, KSA 6.86). É possível inferir que a criação não é uma atividade do homem (no sentido de ser agonista ou causa de processos ou atos), mas de uma passividade; criar é estar aberto, permeável a um pathos, é escoar um pathos. A passividade do artista humano fica notadamente estabelecida já desde $O$ nascimento da tragédia, numa postura que se manterá ao longo da obra nietzschiana:

Não somos nós os verdadeiros criadores deste mundo da arte. Temos certamente, o direito de pensar que, para o verdadeiro criador da arte, somos também imagens e projeções artísticas, e que a nossa glória mais alta é a nossa significação de obras de arte (...) mas na vida quotidiana temos tanta consciência desta função que nos foi atribuída como os guerreiros que estão pintados num quadro podem ter consciência da batalha que representam. (GT/NT, 5, KSA 1.47).

O homem, na sua condição de artista, é apenas um tradutor, um mediador, um médium do jogo vital: "o verdadeiro criador da arte". Não obstante, a criação pode ser entendida de forma diferente em outros textos nietzschianos. Ela aparece como uma capacidade própria, que pulsa no homem, que o instiga à criação de novos valores, que lhe permitiria estabelecer novos sentidos. Conforme essa ótica, o homem pareceria ter um papel ativo na geração desses novos parâmetros, decorrente de sua própria forma de mensurar, oriundo de sua própria medida, de sua própria mudança. Vejamos esta tese pelas palavras de Zaratustra:

Na verdade, os homens deram-se a si próprios a sua regra de bem e do mal. Na verdade não a tomaram nem a encontraram, e não lhes apareceu como uma voz vinda do céu. Foi o homem que deu as coisas o seu valor, a fim de as pôr em segurança; foi ele que lhes deu um sentido humano. É por isso que se chama "homem" - o medidor das coisas. Medir é criar - ouvi, ó criadores! São as vossas medidas que transformam as coisas 
medidas em tesouros e joias. Medir é avaliar; - sem esta avaliação a existência seria uma noz chocha. Ouvi, ó criadores! Os valores mudam, quando os criadores mudam! (Za/ZA, I, Dos mil e um fitos, KSA 4.75).

Nesta passagem do Zaratustra, a capacidade criativa do homem é exaltada: os valores não se encontram nem "aparecem como uma voz vinda do céu", mas surgem de uma avaliação humana, da determinação de um sentido próprio, de uma mensuração de cada indivíduo criador. Este texto contradiria, de forma nítida, a suposta passividade do homem, que encontramos em alguns textos citados anteriormente, como o de $O$ nascimento... É preciso, então, tentar esclarecer as razões dessa oscilação no pensamento nietzschiano. Vemos que, por um lado, a criação é considerada como o resultado das forças da natureza (ela, sim, a genuína "artista", agonista de toda obra de arte, de toda produção de valores), e, por outro, é postulada como uma capacidade, como uma condição inerente a todo criador, a todo homem que seria essencialmente avaliador: aquele que atribui o sentido a todas as coisas. Após essas ponderações, podemos assinalar que, num sentido, a avaliação é entendida como uma passividade no homem (o artista considerado, ele mesmo, como "obra de arte"), e em outro, afirma-se a sua atividade, a sua autonomia, a sua criatividade. Parece, então, conforme os textos analisados, que haveria uma ambiguidade, na postura nietzschiana, com relação à autonomia ou não do homem, enquanto artista, criador de valores.

\section{Sobre a criação e a questão do agir moral}

No tocante à criação de valores, conforme vimos anteriormente, podemos encontrar teses diversas nos textos nietzschianos. Essa divergência na abordagem da questão axiológica, já apontada no âmbito da produção de avaliações estéticas, acentua-se quando analisamos questões da conduta, do denominado "agir ético". Lembremos que Nietzsche é claro e contundente quando coloca 
em xeque a moral tradicional baseada na dicotomia de valores, que os coloca sob os critérios dicotômicos de bem e mal; ele afirma a necessidade de interpretar toda ação humana, para além do bem e do mal. Na natureza, no jogo de forças do vir a ser, tudo diz "sim", e não há nada que possa ser considerado "bom" ou "mau" em "si mesmo". Tudo surge, na dinâmica da vontade de potência, como impulso ao crescimento, à manutenção ou à intensificação da vida.

O pensador alemão é categórico ao questionar as tábuas axiológicas da moral, da metafísica e da religião tradicionais, que tentam impor normas e castigos, que acusam, julgam e penalizam o agir do homem. Essas doutrinas coercitivas baseiam-se, em linhas gerais, na postulação da existência de "sujeitos" livres, dotados de vontade autônoma, capazes de escolher, de agir per se, e, portanto, passíveis de serem premiados ou penalizados. Em Crepúsculo dos ídolos, essa perspectiva repressiva e punitiva da doutrina do livre arbítrio, é severamente criticada, considerada como uma invenção sacerdotal para melhor dominar os homens:

Hoje não temos a menor complacência com o conceito de "livre arbítrio": sabemos demasiado bem o que é - a mais desacreditada artimanha de teólogos que existe, destinada a fazer "responsável" a humanidade no sentido dos teólogos (...). Imaginaram- se os seres humanos "livres" para que pudessem ser julgados, castigados, - para que pudessem ser culpados: por conseguinte, teve que se pensar que toda ação era fruto da vontade, e que a origem de toda ação estava situada na consciência (...). (GD/CI, "Os quatro grandes erros", 7, KSA 6.95).

Como apontamos desde o início, Nietzsche questiona todas as noções que aludiriam a um suposto substrato subjetivo - "razão", "consciência", "sujeito" - e a uma suposta capacidade operativa humana - "vontade", "arbítrio" - libertando o homem de qualquer responsabilidade ou imputabilidade nos seus atos; restituir-se-ia a "inocência do devir". O ser humano é apenas um fragmento do todo, é um ser natural que não pode responder pelo que faz, já que como integrante do mar de forças da vontade de potência 
Uma perspectiva nietzschiana sobre liberdade e necessidade

não tem nenhuma alternativa para agir de outra forma: "Ninguém é responsável por existir, por estar feito deste ou daquele modo, por encontrar-se nestas circunstâncias, neste ambiente." (GD/CI, "Os quatro grandes erros", 8, KSA 6.96). O autor do Crepúsculo dos ídolos sustenta a inocência do devir: tudo é resultado do jogo de forças, do permanente acaso, do imprevisível jogo da vontade de potência. Contudo, o discurso nietzschiano sobre a condição do homem parece aproximar-se, em alguns textos, de um determinismo ou de um fatalismo, que muitas vezes é enunciado de forma explícita, como no aforismo que estamos analisando, que diz na sequência:

A fatalidade do seu ser [do homem] não pode ser destrinchada da fatalidade de tudo o que foi e será. Ele não é consequência de uma intenção, uma vontade, uma finalidade próprias (...). Nós é que inventamos o conceito de "finalidade": na realidade ñ̃o se encontra finalidade... Cada um é necessário, é um pedaço de destino, pertence ao todo, está no todo - não há nada que possa julgar, medir, comparar, condenar nosso ser, pois isso significaria julgar, medir, comparar, condenar o todo... Mas não existe nada fora do todo! (GD/CI, "Os quatro grandes erros", 8, KSA 6.96).

A partir dessas afirmações, podemos concluir que a moral, a religião, a metafísica são construções antropomórficas, com intenções normativas e punitivas, cujo arsenal de noções ficcionais pretende "corrigir" as ações humanas; esses sistemas coercitivos procuram pressionar os homens a agirem "de outra forma". Contudo, não há homens livres, não há vontades espontâneas que nos tornem "capazes" de agir de um modo ou de outro; apenas encontramos avaliações que dependem da conjugação de forças, no jogo do vir a ser. Por isso, todo acontecer seria fatal e necessário, não existiriam intenções individuais, o homem seria um joguete lançado na grande maré do devir universal. Não obstante, Nietzsche, em outros textos, alude a avaliações nobres, saudáveis que estariam em consonância com a vida, com estados de plenitude de força. Essas avaliações não se constituiriam em normativas; seriam apenas apreciações fisiológicas, observações sobre formas de vida que 
afirmam ou se afastam do crescimento e da força; seriam saudáveis ou doentias. Por conseguinte, o questionamento aos moralistas, religiosos, metafísicos seria clínico ou médico; careceria de conotações normativas que indiquem como agir bem ou mal, certo ou errado. Haveria um diagnóstico do estado das forças vitais desses indivíduos que pretendem enquadrar a vida dos homens. É importante destacar que, sob a ótica clínica de Nietzsche, os homens não poderiam fazer outra coisa. Admitir que eles tivessem a capacidade para mudar suas atitudes, seria acreditar na autonomia do seu agir; eles teriam, de "boa vontade", a condição para mudar o rumo de suas ações. Poderíamos, então, dizer "não sejam fracos", "não rejeitem a vida", "não afirmem o além-mundo", etc. Contudo, perante a dinâmica inexorável da vontade de potência, essas exortações pareceriam vácuas e desnecessárias. A formulação de um imperativo implicaria na aceitação da existência de agentes capazes de agir, de cumprir ou não mandamentos, de acatar ou não ordens.

Caberia indagar, nessa mesma linha de questionamentos, em que sentido poderiam ser interpretadas as exortações do Zaratustra, quando conclama: "permanecei fiéis à terra" ou "tendei a realizar o além do homem"? Poderíamos considerar esses enunciados apenas como exortações, como recursos retóricos? Sustentar qualquer mudança de conduta, mesmo que seja na perspectiva da afirmação da terra, do além do homem, ou da celebração da vida, pareceria ainda remeter à autonomia de um agonista, de um protagonista de atos, que teria uma capacidade decisória, uma pretensa aptidão para escolher (mesmo que não seja através da denominada "vontade" ou "faculdade livre"). A questão torna-se ainda mais complexa ao lembrarmos algumas passagens nas quais Nietzsche sustenta a incidência total de sais e outros fatores inorgânicos que seriam determinantes da conduta humana. Se o homem está totalmente determinado por aspectos inorgânicos não teria sentido falar de decisões, opções ou ações na qual ele poderia ser considerado o agonista, já que todos os atos seriam o resultado necessário desses 
fatores antecedentes.

A afirmação da inocência do devir liberta o homem das pressões das doutrinas normativas. Contudo, nos textos nietzschianos, aludir à liberdade do homem, à sua capacidade de agir parece carecer de sentido. Pareceria que a sua postura se aproxima de teses fatalistas ou deterministas, pelo menos no sentido convencional do emprego dessas noções: como a total determinação e destinação dos atos humanos. Essa presunção da nossa análise sobre a negação da liberdade do homem se acentua ainda mais se considerarmos a relevante ideia do eterno retorno. Destacamos que essa ideia somente será mencionada neste artigo, aludindo principalmente a um fragmento póstumo do autor, pois a relevância dessa tese excederia os limites e possibilidades deste artigo, levando-nos a outras análises complexas e minuciosas. O fragmento póstumo aludido reforçaria a convicção de que tudo é fatal (esse termo é empregado literalmente nesse aforismo), mostrando a ausência de qualquer atividade própria do homem, de qualquer protagonismo na realização dos seus próprios atos: "Minha consumação do fatalismo: $1^{\circ}$. Pelo eterno retorno e a pré-existência; $2^{\circ}$. Pela eliminação do conceito de 'vontade'." (Nachlass/FP, primavera de 1884, 25 [214], KSA 11.70).

Este sintético aforismo apresenta teses importantes e de grande significado para a questão que aqui abordamos. O filósofo alemão afirma que consegue justificar a "consumação do fatalismo", baseado em duas asserções. A segunda - aludindo à rejeição da noção de uma vontade operativa - já tematizada neste artigo - destaca que a denominada vontade humana é incapaz de produzir atos, de ser causa, de ser agente capaz de tomar decisões. Já a primeira asserção alude à ideia do eterno retorno, que apenas aparece em três textos publicados por Nietzsche. Os desdobramentos mais detalhados dessa ideia nietzschiana aparecerão nos seus fragmentos póstumos. Não analisaremos aqui, como já apontamos, o profundo sentido de uma tese enunciada de forma eminentemente metafórica e que deu lugar a numerosas e divergentes interpreta- 
ções, cuja exegese demandaria uma análise muito cuidadosa, excedendo os propósitos desta reflexão. Contudo, queremos chamar a atenção que, no fragmento em estudo, o eterno retorno é apresentado essencialmente vinculado à pré-existência, entendida como existência prévia, isto é, o que acontece agora, hoje, neste mesmo momento, já aconteceu antes, nada tem de novo, é repetição do realizado, atualização de algo consumado de antemão, sem nenhuma possibilidade de ser alterado por parte do homem ou por qualquer outro fator. Esse aforismo parece corroborar as ideias essenciais do conhecido aforismo 341, de A gaia ciência, em que a figura de um demônio lança a sentença do irrevogável, do aspecto fatal de todos os nossos atos: "Esta vida tal qual a vives atualmente, é preciso que a revivas ainda uma vez mais e uma quantidade inumerável de vezes e nada haverá de novo. Pelo contrário." (FW/GC, 341, KSA 3.570). O aforismo da primavera de 1884, ao sustentar uma tese fatalista e vincular-se ao eterno retorno, parece confirmar uma orientação do Nietzsche na sua compreensão do agir do homem: nega-se a vontade individual, tudo já preexiste à existência atual, tal como já o vivemos anteriormente, uma e outra vez; em suma, a existência humana estaria dominada pela fatalidade, pela reedição infinita do mesmo, pela ausência de novidade, pela total impossibilidade de criar caminhos inéditos, pela incapacidade de forjar novos atos.

\section{Considerações finais}

Nestas ponderações finais, tentaremos retomar o caminho transitado nas reflexões deste artigo, destacando que a questão da liberdade e da necessidade, no pensamento de Nietzsche, nos leva a complexos desdobramentos, a atalhos aparentemente sem saída, do ponto de vista discursivo. Vimos que o pensador alemão, ao refletir sobre a liberdade, apresenta teses diversas que, às vezes, parecem levar a contradições argumentativas aparentemente insolúveis. As noções de liberdade e de necessidade adquirem novos 
sentidos, diferindo notadamente das teses da moral, da metafísica e da religião tradicionais, podendo ser predicadas exclusivamente da vontade de potência. O homem não seria livre como indivíduo, como sujeito autônomo, como protagonista de atos, que delibera e escolhe determinado rumo para suas ações, mas como integrante da vontade de potência. Nesse sentido, liberdade pode ser entendida como "realização da necessidade", como obediência ao pathos do devir. O individual estaria submerso no fluxo do vir a ser universal. Nas análises realizadas aqui, e na abordagem de alguns textos publicados e de outros fragmentos póstumos, mostramos que essa perspectiva pode indicar uma compreensão determinista ou fatalista da ação humana. O fatalismo é enunciado de forma taxativa, por exemplo, em Crepúsculo dos ídolos, nos capítulos: Os quatro grandes erros e A moral como contra natureza. Na singular perspectiva nietzschiana sobre os atos humanos, apontamos divergências, em torno da problemática da liberdade, encontradas em diferentes textos. Em alguns deles, de caráter eminentemente ético, apresenta-se a exigência de que o homem assuma determinadas atitudes, na realização de avaliações, que implicariam o protagonismo, a sua capacidade de agir. Lembremos, por exemplo, os discursos do Zaratustra quando exorta aos homens criadores a gerarem novas tábuas, novos sentidos; isso suporia sustentar o protagonismo humano, a realização de atos per se, sem depender de "nenhuma voz oriunda dos céus". Em outros textos, mostramos que o autor indica o contrário, destaca enfaticamente a impossibilidade de alterar, de qualquer forma, os rumos da realidade; o homem estaria fatalmente integrado a tudo o que é, à predeterminação inexorável das forças da natureza.

É possível perceber uma oscilação nessa diversidade de escritos nietzschianos: em alguns momentos, a liberdade é sugerida, em outros, é negada. A questão da necessidade também é enunciada de forma ambivalente em diversos textos: o necessário, o fatal é, por vezes, enunciado, enquanto em outras oportunidades, é con- 
testado, por ser oriundo do emprego de termos vácuos, como o de causalidade.

Percebemos que indicar essas ambivalências, nas reflexões nietzschianas sobre liberdade e necessidade merece uma avaliação em um espectro teórico mais amplo. Caso essas asserções fossem interpretadas em um sentido literal, poderíamos assinalar que existiriam contradições no seu pensamento. Contudo, o discurso nietzschiano não pode ser abordado a partir de uma lógica linear, em que os conceitos empregados possam ser entendidos da "mesma forma" em todos os textos e aforismos. Nesse sentido, é importante, neste tramo final da nossa reflexão, esclarecermos algumas características do estilo nietzschiano, no qual as contradições, as aporias, os paradoxos parecem ser um aspecto constitutivo essencial de um pensamento aberto às vicissitudes oscilantes da vontade de potência.

Acreditamos que as ponderações de Stegmaier (2013), na coletânea dos seus artigos, organizada no Brasil sob o título As linhas fundamentais do pensamento de Nietzsche, assim como os comentários de Giacoia (2013), na apresentação deste livro, podem nos ajudar a refletir sobre a problemática da liberdade e da necessidade, em Nietzsche, que - conforme os textos estudados - parece nos abandonar em atalhos aparentemente sem saídas, em termos do discurso racional. Inicialmente, é importante levar em conta as afirmações de Giacoia, quando destaca que o filósofo do Zaratustra, ao discutir temas relevantes da filosofia ocidental - tais como o da liberdade, aqui em questão - produziria não doutrinas ou teorias e conceitos de pretensa validade universal, mas: “(...) antidoutrinas, integradas por anticonceitos - componentes fundamentais desse sistema filosófico 'proprium et ipssissimum' nos quais somos permanentemente lançados na impermanência, na ousadia do desconhecido, no horizonte infinito dos paradoxos filosóficos, onde há somente mar, mar, mar..." (Giacoia, 2013, p. 28).

Assim, o pensamento nietzschiano visa focalizar as oscilações do vir a ser, as mudanças de forças do jogo da vontade de 
Uma perspectiva nietzschiana sobre liberdade e necessidade

potência; daí que os termos, as ideias empregadas se apresentem de uma maneira proteiforme e mutável. Talvez as pretensões de um discurso lógico e silogístico, que se proponha esmiuçar as noções de "necessidade" e "liberdade", estejam presas a um pensar estático, que constrói conceitos identitários, que almejam "fixar" o devir. No entanto, o devir é refratário à estabilização ou fixidez. Nesse sentido, noções como "determinismo", "causalidade", "necessidade", "liberdade", "vontade livre" e outras levem necessariamente a aporias e contradições, pois não poderiam exprimir a dinâmica da vontade de potência. Por isso, conforme esclarece Stegmaier, Nietzsche reluta em constituir "doutrinas", o que implicaria na vã tentativa de congelar, de fixar o mar irrefreável do devir, mas forja uma "filosofia em máscaras" e "coloca o leitor num labirinto (...) no qual é obrigado a procurar sozinho seus próprios caminhos, nos quais em algum momento acabará por se perder." (Stegmaier, 2013, p. 105, 108). Daí, Nietzsche nos lançar sempre na intempérie de questões filosóficas sem saídas. Sua crítica às doutrinas estabelecidas, e a todos os conceitos basilares da tradição, contesta termos como "determinismo" ou "livre arbítrio", colocando-os num semelhante patamar argumentativo, mesmo que aparentem aludir a situações "factuais contraditórias":

Se alguém chegasse a vislumbrar a néscia rusticidade do famoso conceito de "livre arbítrio" até chegar a afastá-lo do seu espírito, eu lhe rogaria que desse mais um passo e afastasse do seu cérebro o contrário desse pseudo-conceito, isto é "determinismo", que conduz ao mesmo abuso das noções de causa e efeito. (JGB/BM. 21, KSA 5.35).

O questionamento dos conceitos da tradição filosófica como livre arbítrio, determinismo, causa e efeito e outros - que Nietzsche inicia desde Sobre verdade e mentira no sentido extra moral até o final de sua obra, é uma resposta plausível do filósofo a qualquer questionamento a uma possível ambiguidade na sua 
postura perante o agir humano: se é agonista, se é ativo ou não nesse agir.

Acreditamos que o pensador abre um caminho de meditação para esse problema, muito mais de que tentar elucidá-lo nos termos conceituais da tradição argumentativa. Não haveria respostas, no plano das conceituações tradicionais, perante a velha antinomia de liberdade e necessidade. Ao usar de forma explícita essas conceituações - por exemplo, quando fala em fatalidade, ou quando alude à ação determinante do sal no organismo humano - parece manter-se na órbita dos conceitos questionados; parece, ainda, empregar noções, como as de causa e efeito. Na lógica do discurso silogístico da tradição filosófica, poderia se alegar um uso ambivalente e até contraditório dessas noções. Contudo, a proposta nietzschiana, ao pensar a liberdade no homem, é refletir a partir do parâmetro da vontade de potência - parâmetro este refratário a essas conceituações. Como bem assinala Stegmaier (2013, p. 109), o estilo nietzschiano sempre é deliberadamente "polêmico, ataca determinações estabelecidas sem estabelecer novas; o leitor tem, ele próprio, de refletir sobre elas. É, numa palavra [o estilo nietzschiano], experimental, convida a aventuras do pensamento, que em parte alguma estão seguras, e que invariavelmente acabam na incerteza." Daí que a questão da liberdade e da necessidade, na filosofia nietzschiana, aparente submergirmos nos paradoxos e contradições; contudo, muito além de um convite à resolução silogística e/ ou sistemática da questão do agir humano (determinado ou não determinado), acreditamos que nesse aspecto, suas reflexões consistem em uma proposta experimental ou aventura do pensamento, de adentrarmos na incerteza e na meditação sobre as possibilidades e impossibilidades desse agir. 


\section{A Nietzschean perspective on freedom and necessity}

Abstract: We address nietzschiana interpretation on the issue of freedom and necessity. We show how the German philosopher disputes notions of philosophical tradition, linked to this problem, as "cause and effect", "subject", "i", "will" etc. He points how these concepts would be just anthropomorphic constructs that cannot unravel the nature of the actions; managed only by the power control game of the will of power. We show that Nietzsche, even with this radical criticism of the concepts of tradition, continues to employ notions such as "fatality", "necessity" that seem to resend to the anthropomorphic conceptualization questioned. We indicate how the author of Zaratustra manages to overcome the objections that may be made to an oscillating thought, which sometimes seems to deny and affirm freedom at different times of his work. We agree with interpreters who point out that Nietzsche's style deliberately chooses to raise paradoxes and apparent apores, since his goal, before establishing a doctrine or a consolidated theory about freedom and necessity, is an attempt to instigate new reflections, new thought experiences, new paths of meditation on the action of man.

Keywords: perspectives, freedom-need, causality, subject, will. 


\section{Referências}

NIETZSCHE, Friedrich. Sämtliche Werke. Kritische Studienausgabe (KSA), 15 vols. (Organizada por Giorgio Colli e Mazzino Montinari), Berlim: Walter de Gruyter \& Co., 1988.

. Genealogia da moral. Trad. de Paulo César de Souza. São Paulo: Cia. das Letras, 1998.

. Além do bem e do mal. Trad. de Paulo César de Souza. São Paulo: Cia. das Letras, 1999.

- A gaia Ciência. Trad. de Paulo César de Souza. São Paulo: Cia. das Letras, 2001.

. Aurora. Trad. de Paulo César de Souza. São Paulo: Cia. das Letras, 2004 .

. Crepúsculo dos ídolos. Trad. de Paulo César de Souza. São Paulo: Cia. das Letras, 2006.

BARRENECHEA, Miguel Angel de. Nietzsche e a liberdade. Rio de Janeiro: 7 Letras, 2000; 2. ed. 2008.

. Nietzsche e o corpo. Rio de Janeiro: 7 Letras, 2008; 2. ed. 2017. et al (org.). Nietzsche e as ciências. Rio de Janeiro: 7 Letras, 2011.

BLONDEL, Erik. Nietzsche, le corps et la culture. Paris: PUF, 1985.

. As aspas de Nietzsche: filologia e genealogia. In: MARTON, Scarlett (Org.). Nietzsche hoje? Trad. Milton Nascimento. São Paulo: Brasiliense,1986, p. 110-139.

DIAS, Rosa Maria. Nietzsche, vida como obra de arte. Rio de Janeiro: Civilização Brasileira, 2011.

FINK, Eugen. A filosofia de Nietzsche. Trad. Joaquin L. D. Peixoto. Lisboa: Presença, 1983.

GIACOIA JR., Oswaldo. Introdução. In: STEGMAIER, Werner. As linhas fundamentais do pensamento de Nietzsche. Trad. O. Giacoia Jr. et al. Petrópolis: Vozes, 2013.

ITAPARICA, André. "Causalidade". In: GEN. Dicionário Nietzsche. São Paulo: GEN/Loyola 2016, p. 137-139. 
Uma perspectiva nietzschiana sobre liberdade e necessidade

. "Livre arbítrio". In: GEN. Dicionário Nietzsche. São Paulo: GEN/ Loyola 2016, p. 288-290. 2019.

. Idealismo e realismo na filosofía de Nietzsche. São Paulo: Unifesp,

KANT, Immanuel. Crítica de la razón pura. Trad. José R. Armengol. Buenos Aires: Losada, 1979.

. Crítica da razão prática. Trad. Artur Morão. Lisboa: Ed.70, 1997.

LEMM, Vanessa. Nietzsche's animal philosophy: culture, politics, and the animality of the human being. Nova York: Fordham University Press, 2009.

LÖWITH, Karl. Nietzsche e a completude do ateísmo. Tradução Sônia S. Goldbert. In: MARTON, Scarlett. Nietzsche hoje? São Paulo: Brasiliense, 1985. p. 140-167.

MARTON, Scarlett. "Da biologia à física: vontade de potência e eterno retorno do mesmo. Nietzsche e as ciências da natureza". In: BARRENECHEA, Miguel Angel de et al. (org.). Nietzsche e as ciências. Rio de Janeiro: 7 Letras, 2011. p. 114-138.

MÜLLER-LAUTER, Wofgang. A doutrina da vontade de poder em Nietzsche. Apresentação Scarlett Marton. Trad. Oswaldo Giacoia Jr. São Paulo: Annablume, 1997.

NASSER, Eduardo. "Necessidade". In: GEN. Dicionário Nietzsche. São Paulo: GEN/Loyola 2016, p. 324-326.

STEGMAIER. Werner. As linhas fundamentais do pensamento de Nietzsche. Tradução Giacoia Jr. O. et al. Petrópolis: Vozes, 2013.

STIEGLER, Barbara. Nietzsche et la biologie. Paris: PUF, 2001. . Nietzsche et la chair: Dyonisos, Ariane, Le Christ. Paris: PUF, 2005.

Enviado: 16/04/2020

Aceito:25/07/2020 